\title{
Economic implications of multi-layer safety projects for flood protection
}

\author{
V. Tsimopoulou \\ Delft University of Technology, Netherlands
}

HKV Consultants, Netherlands

J.K. Vrijling

Delft University of Technology

M. Kok

Delft University of Technology, Netherlands

HKV Consultants, Netherlands

S.N. Jonkman

Delft University of Technology

J.W. Stijnen

HKV Consultants, Netherlands

ABSTRACT: Looking at flood risk management developments that have lately taken place in the Netherlands, the emergence of a virtual liking of disaster preparation measures is perceptible. Investments in multilayer safety projects are one of the most popular outlets of this trend. Multi-layer safety has raised several discussions about its cost-efficiency. This paper contributes in these discussions by clarifying the economic implications of multi-layer safety from a rational perspective.

\section{INTRODUCTION}

Recent experience of large-scale water disasters such as Hurricane Katrina in 2005 and the Great Eastern Japan Earthquake and Tsunami in 2011 has reminded mankind that disasters cannot be ruledout. Unprecedented low-probability events can happen even in the most well monitored areas, causing major social-economic disruption. Failing to prepare for them may imply taking a risk that is not socially acceptable, but how much preparation for disasters can a modern society afford?

Looking at flood risk management developments that have lately taken place in the Netherlands, the emergence of a virtual liking for disaster preparation measures is perceptible. Various technical studies have been made available presenting the effectiveness of such measures in the mitigation of expected fatalities and material damage (see for example De Bruijn \& Klijn 2012). One of the most popular outlets of this trend is a suggestion in the National Water Plan of the Netherlands (2009) for the future to contemplate investments not only in floodprevention measures, where the Dutch state has been investing heavily since 1960 (Van Dantzig \& Kriens 1960), but also in measures for the mitigation of losses. The existence of such a compound of measures signifies a so-called multi-layer safety system. The term multi-layer safety has been invented in the Netherlands, where flood-control measures are clas- sified into three safety layers. Layer 1 comprises measures for the prevention of flooding, such as dykes and storm-surge barriers, layer 2 comprises spatial solutions for the mitigation of losses, such as flood proofing or relocation of buildings to safer places, and layer 3 comprises emergency management measures, such as evacuation. The same concept can be found with more names in international literature, such as multiple lines of defence (Lopez et al. 2007), or multi-level approach. A characteristic example of a multi-layer safety system can be found on the coast of Tohoku in Japan that was afflicted by the tsunami of 2011. In that area measures representative of all three layers were present before the disaster (Tsimopoulou et al. 2011), while there are plans to re-implement similar solutions in the future (Jonkman et al. 2012).

Multi-layer safety has raised several discussions about its cost-efficiency. Previous studies have shown that combining flood-prevention with lossmitigating measures is generally speaking not costeffective (Vrijling, 2009). For a system that resembles the Netherlands, it has been shown that despite prevention, it is cost-effective to also invest a small amount in emergency management (Kolen \& Kok, 2011). This paper contributes in the above discussions by clarifying the economic implications of multi-layer safety from a rational perspective. In particular the objectives of the forthcoming analysis are 1) to clarify what is the most relevant information for decision makers regarding investments in multi-layer safety, and 2) to provide guidance on 
how to derive this information by means of costbenefit analysis. The analysis is facilitated through a fictitious case study that refers to a coastal area, where the implementation of a multi-layer safety project is contemplated.

\section{ECONOMIC DECISION PROBLEMS FOR MULTI-LAYER SAFETY}

Whether multiple layers of safety are present in a system and which ones are prioritized can vary significantly in different countries and regions depending on a variety of conditions that can be highly time-dependent. Some of them are the degree of public awareness of flood risk (see e.g. Priest et al. 2008) the occurrence and severity of flood events in the recent past (see e.g. Esteban et al. 2012), the value of the area that needs to be protected in terms of human life, economic assets and natural environment (see e.g. Commissie Toetsing Uitgangspunten Rivierdijkversterking, 1993), and the degree of flexibility in policy-making that allows economic resources to be available for financing flood risk management projects (see e.g. Huizinga F. 2012). These conditions determine the preferences on a political level regarding safety against flooding.

When decision-makers order their preferences in a consistent manner, it can be said that they adopt a rational behaviour (Jongejan et al. 2012). In this paragraph the information that is relevant for a rational decision-maker, whose ultimate preference is to maximize the net economic benefits of investments in flood risk management is clarified. The reason that we choose to use the maximization of net economic benefits as the ultimate purpose is because such a preference is supposedly consistent with the criterion that is being used for the formulation of flood safety policy in the Netherlands, i.e. the formulation of safety standards in dyke-ring areas (Van Dantzig, 1956, Kind, 2013). Hence a rational decision-maker in the Netherlands would choose this economic criterion to derive the most appealing policy options, which can be evaluated by means of cost-benefit analysis.

Taking a closer look to the decision-making process regarding investments in multi-layer safety, it can be realized that there is a number of different questions that a decision-maker might need to have answered via an economic evaluation. This is because when a multi-layer safety system is contemplated, measures with different functions need to be combined, and their combinations need to be prioritized. What decision-makers would be interested to know is first of all whether it is wise to invest in a certain combination of measures or not, i.e. whether a certain project is economically justifiable or not. Provided that the answer to this question is yes, they would need to know how much to invest in every measure in order to maximize the expected utility of the project, i.e. its net present value. Yet in reality this piece of information is not sufficient, as it refers to a "fixed" project, i.e. a project consisting of floodcontrol measures that are a priori known and might have been chosen arbitrarily or on basis of noneconomic criteria. An optimized "fixed" project may be more costly than other optimized solutions, which can be either another multi-layer safety project or a single-layer solution, e.g. the improvement of an existing dyke in the case of the Netherlands. An economic evaluation will be more comprehensive if the different optimized projects are prioritized based on their net present values.

The three above-presented types of information constitute different types of decision problems; the first type is an "accept / reject" problem, the second an "optimization" problem, while the third a "prioritization" problem. An explicit indication of the type of problem that needs to be solved is prerequisite for a competent cost-benefit analysis (Fischhoff et al. 1981). This is mainly because the decision problem determines which economic criterion is the most appropriate for deriving conclusions (Pearce \& Nash 1981). Given the adoption of a rational behaviour that orders preferences based on net economic benefits, the three types of decision problems are solved with a different utilization of the net present value criterion, as presented in the following table.

Table 1. Classification of economic decision problems for multi-layer safety projects

\begin{tabular}{lll}
\hline Decision type & Evaluated object & Decision criterion \\
\hline Accept / Reject & "Fixed" project & $\mathrm{NPV}>0$ \\
Optimization & "Fixed" project & $\mathrm{NPV}_{\text {opt }}=\mathrm{NPV}_{\max }$ \\
Prioritization & Various projects & $\mathrm{NPV}_{\mathrm{opt}}=\max \left\{\mathrm{NPV}_{\mathrm{i}}\right\}$ \\
\hline
\end{tabular}

\section{CASE STUDY CONTEXT}

Assume a flood prone coastal area that is currently not in use. The local authorities are planning to develop this area for agricultural production, and also to use a part of it as a residential area for farmers. After investigation of the technical possibilities it has been concluded that there are two flood-control measures that can be undertaken, the building of a dyke along the waterfront, which is a measure of layer 1 for prevention of flooding in the entire floodprone area, and the placement of the residential area on an artificial mound, which is a measure of layer 2 for the mitigation of losses. The local authorities have decided to invest in both measures, developing a multi-layer safety system (figure 1). 


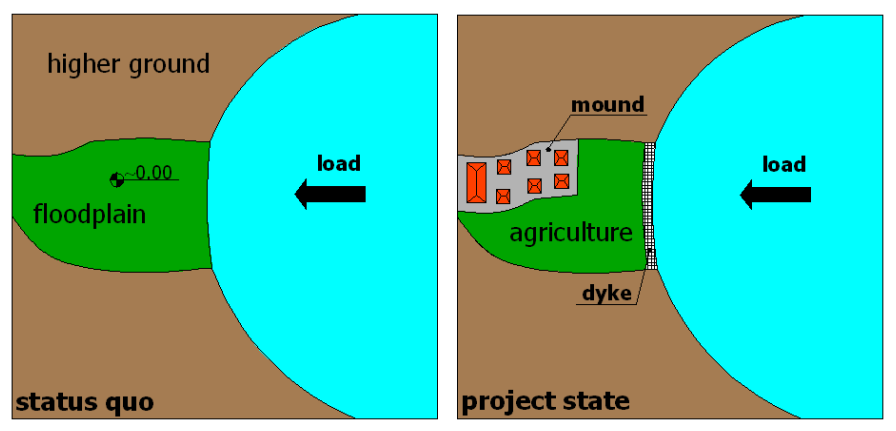

Figure 1. Status quo and project state of the case study area.

This is in fact a fixed project, since the combination of measures has been a priori decided. The information that the local authorities need to derive by means of cost-benefit analysis is how much to invest in every measure in order to minimize the total cost of the system during its lifetime, and whether such an investment is economically justifiable. These are the optimization and accept/reject decision problems of table 1.

\section{COST-BENEFIT ANALYSIS MODEL}

In order to solve the above-presented decision problems a numerical model for cost-benefit analysis has been developed, which is based on a number of assumptions that are listed below. The assumptions focus on keeping the problem as simple as possible, so that a better understanding and interpretation of the results becomes possible.

- There are no budget restrictions associated with the project.

- There is no safety standard that the project needs to comply with.

- The project has an infinite lifetime.

- The flood-control measures need no maintenance during their lifetime.

- Apart from safety against flooding, the project has no other additional benefits.

- The analysis is made for stationary conditions, i.e. no uncertainties over time are taken into account.

- The costs of investment in the two measures are linear functions of their crest levels, and their fixed construction costs are zero (figure 2).
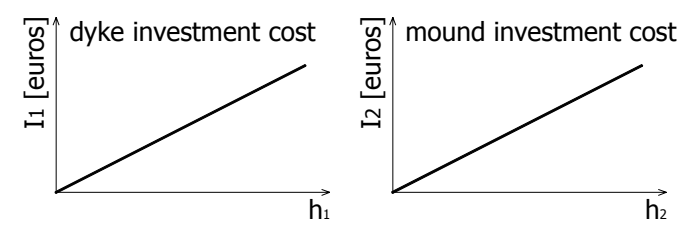

Figure 2. Investment functions

- The annual water level in front of the dyke follows an exponential distribution.

- There is only one failure mechanism of the dyke; breakage caused by overtopping.
- In case of flooding the inundation level in the entire protected area is immediately equal to the incoming water level, i.e. water level in front of the dyke.

- Human losses and material losses in the village and in agriculture are constant and linear functions of the incoming water level (figure 3).

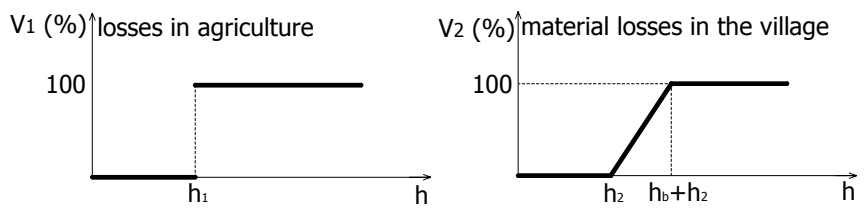

V3 (\%) human losses

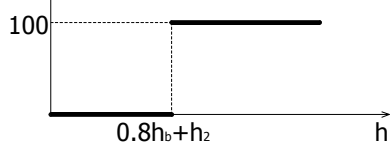

Figure 3. Losses functions

The variables that are present in the model are summarized in the table below.

Table 2. Cost-benefit analysis variables

\begin{tabular}{lcc}
\hline Description & Unit & Symbol \\
\hline Incoming water level & $\mathrm{m}$ & $\mathrm{h}$ \\
Crest level of the dyke & $\mathrm{m}$ & $\mathrm{h}_{1}$ \\
Crest level of the mound & $\mathrm{m}$ & $\mathrm{h}_{2}$ \\
Surface of mound & $\mathrm{m}^{2}$ & $\mathrm{~S}$ \\
Length of the dyke & $\mathrm{Km}$ & $\mathrm{L}$ \\
Number of inhabitants & {$[-]$} & $\mathrm{N}$ \\
Height of buildings & $\mathrm{m}$ & $\mathrm{h}_{\mathrm{b}}$ \\
Value in agriculture & $€$ & $\mathrm{~V}_{1}$ \\
Material value in the village & $€$ & $\mathrm{~V}_{2}$ \\
Cost of human loss & $€$ & $\mathrm{~V}$ \\
Unit cost of dyke per Km length & $€ / \mathrm{m}$ & $\mathrm{C}_{1}$ \\
Unit cost of mound & $€ / \mathrm{m}^{3}$ & $\mathrm{C}_{2}$ \\
Discount rate & {$[-]$} & $\mathrm{r}$ \\
Shift parameter of water level pdf & {$[-]$} & $\mathrm{A}$ \\
Scale parameter of water level pdf & {$[-]$} & $\mathrm{B}$ \\
\hline
\end{tabular}

As explained before, from a rational cost-benefit perspective the condition for optimization is that the invested amount maximizes the net present value of the project, which is equivalent to minimizing the total cost in the system during its lifetime. The total cost consists of the cost of investment and the expected losses throughout lifetime. The model computes the total cost for all possible combinations of investments in the dyke and the mound, indicating in the end the combination that results in the minimal cost. The detailed structure of the model can be seen in figure 4. 


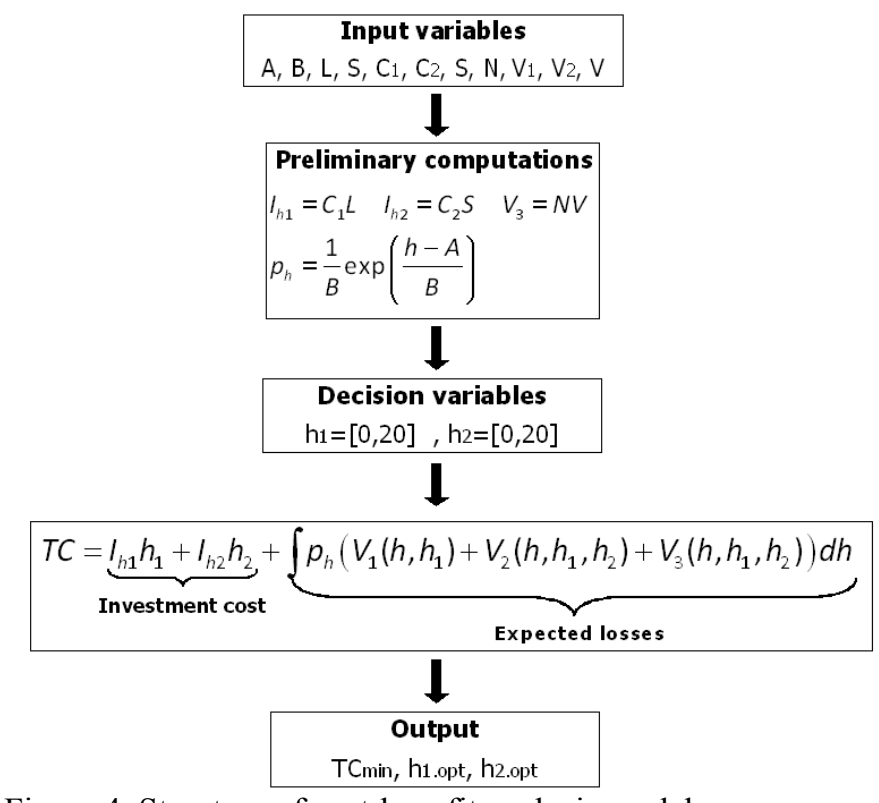

Figure 4. Structure of cost-benefit analysis model

Before undertaking the optimal project, it needs to be checked whether this project is economically justifiable or not, i.e. whether its net present value is greater than zero (see table 1). Given the assumptions that the only benefit is the reduction of expected losses and that there are no maintenance costs, the net present value of the project is given by the following equation:

$$
N P V=\Delta L-I
$$

where, $\Delta \mathrm{L}=$ reduction of expected losses, and $\mathrm{I}=$ total investment cost.

\section{SENSITIVITY ANALYSIS}

The above-presented model has been used for a sensitivity analysis to the input variables with the purpose of getting some idea of what the optimal solutions can be within the context of the case study. Running the model several times for variations of the input variables one by one, different optimal solutions can be derived. As base-values for the variables, data representative for a village in the Netherlands were used. In the one-by-one variable variations though, extreme cases were also captured that could be relevant for other places in the world, such as water levels with exceedance probabilities that resemble typhoons and tsunamis, investment costs in one measure that are much higher than those of the other etc.

The extracted optimal combinations of dyke height and mound height are presented in the following graph (figure 5). In this graph, most of the points are on the y-axis, indicating that in most of the cases investing only in the dyke minimizes the cost. For variations of the costs per meter height of the dyke and the mound $\left(I_{h 1}, I_{h 2}\right)$, there are some cases that the optimal solution is to invest in both measures.

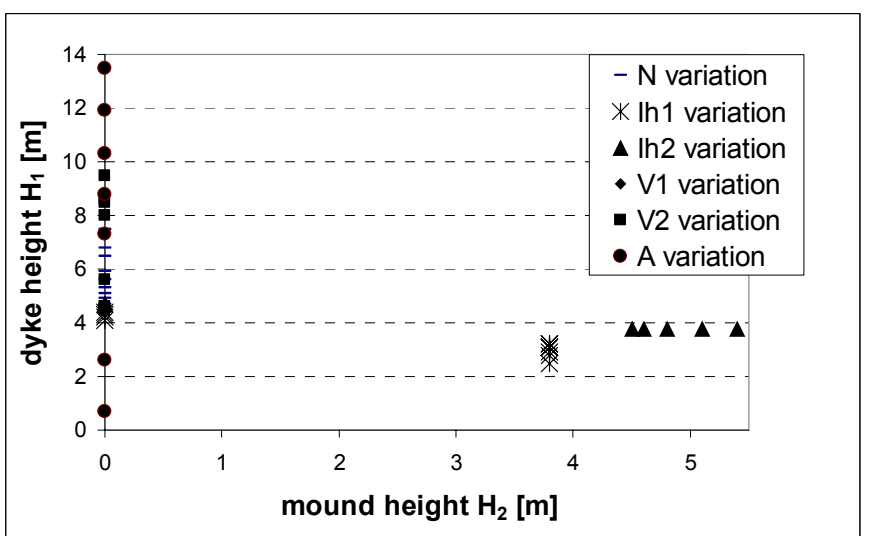

Figure 5. Overview of optimal solutions derived from the sensitivity analysis

According to the analysis, from a cost-benefit perspective multi-layer safety seems to only be preferable when the cost of the dyke per meter height becomes at least five times higher than the cost of the mound per meter height (figure 6).

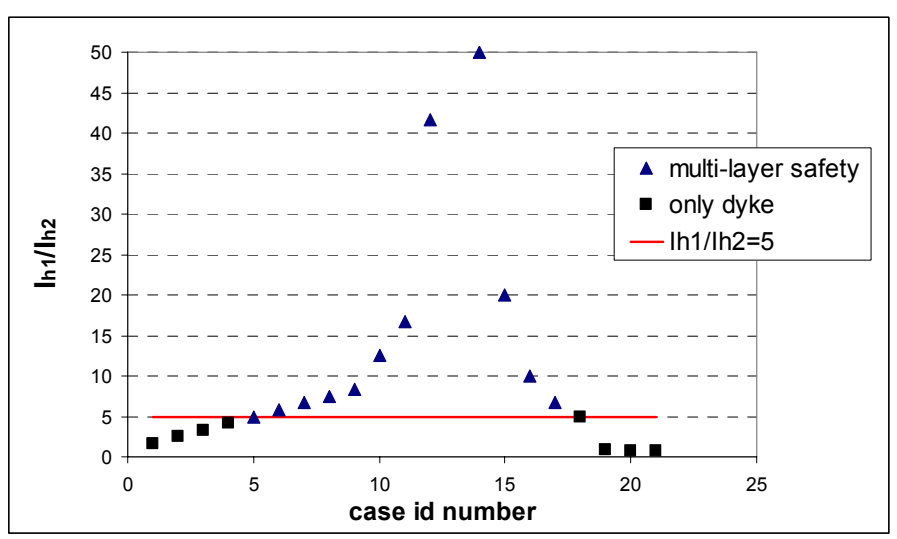

Figure 6. Overview of optimal solutions derived from the sensitivity analysis

Despite the broad range of values that has been tested, variations in the rest of the variables did not suggest departure from the single-layer system. This result does not provide enough evidence though for one to conclude that the rest of the variables do not affect the outcome of the CBA. This can be coincidental for their combination with the fixed values used for the remaining variables. For this reason the derived condition for investing in multi-layer safety can only be used as an indicative rule of thumb at the premature stages of an analysis. For the final decision upon investments, a detailed site-specific cost-benefit analysis is necessary.

\section{SPATIAL DISTRIBUTION OF EXPECTED LOSSES}

A check of the expected losses in the derived optimal solutions shows that their distribution in the system follows a certain pattern; the direct expected 
losses due to failure of the dyke, i.e. the expected losses in agriculture, are higher than the expected losses in the area that is also protected by the mound when multiple layers of safety are implemented. In the cases of a single-layer solution, the expected losses in agriculture are lower than the expected losses in the village, including expected fatalities (figure 7).

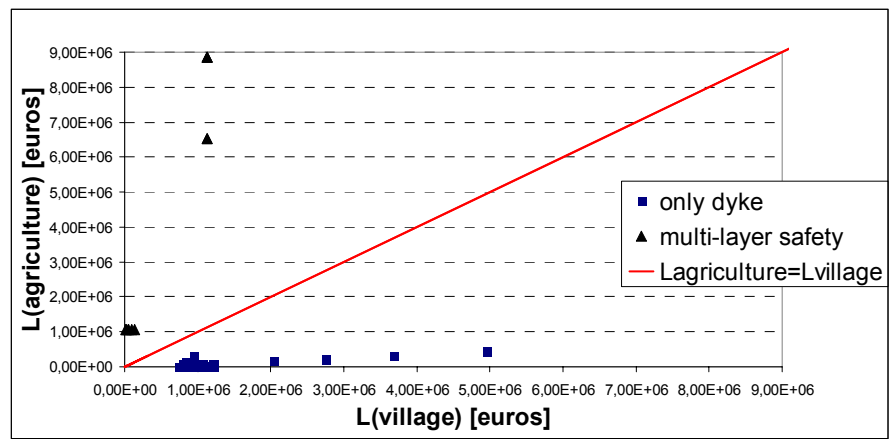

Figure 7. Distribution of expected losses in optimal strategies

Provided that the economic value of the village including human life is higher than that of the agricultural land, the above graph suggests that undertaking a multi-layer safety project implies a larger reduction of risk in the village than in agriculture, while when undertaking the dyke project, the risk reduction in agriculture is higher than that in the village. This shows that protecting areas within a system with multiple layers of safety results in a spatial distribution of economic benefits that is different than the distribution of benefits when a single-layer safety scheme is chosen.

However this gives no information on the absolute reduction of risk, and on whether this reduction becomes higher or lower by undertaking a multilayer safety project. This finding is therefore relevant for cases that a certain spatial distribution of benefits is desirable in the system, so that some areas benefit more/less than others. In those cases undertaking multi-layer safety projects would be recommended. It should be noted though that engaging such a preference implies setting different priorities in decision-making. Instead of ordering alternatives based on their net present value, a cost-effectiveness criterion is used, which will probably indicate an optimal project other than the one that has the highest net present value. This means departure from rationality on decision-making level, and adoption of a risk-averse or a risk-prone behaviour.

\section{CONCLUSIONS}

Multi-layer safety has raised several discussions about its cost-efficiency. This paper contributes in these discussions by presenting the economic implications of multi-layer safety from a rational perspective. Such a perspective assumes that decision- makers order their preferences regarding investments in flood risk management in a consistent manner. In the case of the Netherlands, consistency in the ordering of preferences is promoted when decisions upon investments are made on the same grounds that safety standards are derived, i.e. by means of maximizing the net economic benefits of investments.

In a cost-benefit analysis regarding investments in multi-layer safety, there are various types of decision problems that may need to be solved. These problems need to be explicitly defined. Given the adoption of a rational behaviour the different types of problems are solved with a different utilization of the net present value criterion.

The demonstrated cost-benefit analysis numerical model can be mainly used to solve "optimization" decision problems, but also to prioritize different projects that contain the flood-control measures that the model takes into account. It can also be easily expanded to include more measures of all the safety layers. In order to use it in real-life applications, the validity of its assumptions in the new case need to be checked, and appropriate modifications be made.

Within the context of the demonstrated case study, investing in the multi-layer safety project proves to be optimal when the cost of the dyke per meter height becomes much higher than the cost of the mound per meter height. This finding could be used as a rule of thumb in the early design stages of a flood protection system.

A check of the expected losses in the derived optimal solutions shows that their distribution in the system follows certain patterns. This shows that protecting areas within a system with multiple layers of safety results in a spatial distribution of economic benefits that is different than the distribution of benefits when a single-layer safety scheme is chosen. For this reason, in cases that a certain spatial distribution of risk reduction is desirable, it is recommended to also consider investments in multilayer safety.

\section{REFERENCES}

Central Dutch Government (2009), 2009-2015 National Water Plan,

http://english.verkeerenwaterstaat.nl/english/Images/NWP \%20english_tcm249-274704.pdf

Commissie Toetsing Uitgangspunten Rivierdijkversterking. 1993. Advies van de commissie (in Dutch)

De Bruijn K.M., Klijn F. \& Knoeff J.G. 2012. Unbreachable embankments? In pursuit of the most effective stretches for reducing fatality risk. proc. Flood Risk 2012 Conference. Rotterdam

Esteban, M., Tsimopoulou, V., Shibayama, T., Mikami, T., Ohira., K. 2012. Analysis of tsunami culture in countries affected by recent tsunamis. proc. Sustain 2012 Conference. Kyoto 
Fischhoff B., Lichtenstein, S., Slovic, P., Derby, S.L. \& Keeney, R. 1981. Acceptable risk. Cambridge University Press

Huizinga. F. 2012. The economics of flood prevention, A Dutch perspective. CPB background document: http://www.cpb.nl/en/publication/economics-floodprevention

Jongejan, R.B., Jonkman, S.N. \& Vrijling, J.K. 2012. The safety chain: a delusive concept. Safety Science Issue 5 Vol. 50: 1299-1303

Jonkman, S.N., Yasuda, T., Tsimopoulou, V., Kawai, H., Kato, F. 2012. Advances in coastal disasters risk management: Lessons of the 2011 Tohoku tsunami. proc. ICCE 2012. Santander

Kind, J.M. 2013. Economically efficient flood protection standards for the Netherlands. Journal of Flood Risk Management. DOI:10.1111/jfr3.12026

Kolen, B. \& Kok, M. 2011. Optimal investment in emergency management in a multi layer flood risk framework. proc. $5^{\text {th }}$ International Conference on Flood Management. Tokyo

Lopez J. et al. 2008. Comprehensive Recommendations Supporting the Use of the Multiple Lines of Defense Strategy to

Sustain Coastal Louisiana (Version I): http://www.saveourlake.org/PDF-

documents/MLODSreportFINAL-12-7-08withcomments.pdf

Pearce D. W. \& Nash C. A. (1981), The Social Appraisal of Projects: A text to cost-benefit analysis, The Macmillan Press Ltd., London

Priest, S.J., Clark, M.J. \& Colclough, S. 2008. Public awareness of flood risk: The Role of the Environment Agency Flood Map - Nominated report submitted to the ESRC, June 2008

Tsimopoulou V. et al. (2012), A multi-layer safety perspective on the tsunami disaster in Tohoku, Japan, proc. of Flood Risk 2012 Conference, Rotterdam

Vrijling J.K. (2009), The lessons from New Orleans, Risk and Decision Analysis in Maintenance Optimization and Flood Management, IOS Press, Delft

Van Dantzig, D. 1956. Economic decision problems for flood prevention. Econometrica 24:276-287

Van Dantzig, D. \& Kriens, J. 1960. The economic decision problem of safaguarding the Netherlands against floods. Technical Report, report of the Delta Committee. The Hague (in Dutch) 